\title{
Tamoxifen promotes apoptosis and inhibits invasion in estrogen-positive breast cancer MCF-7 cells
}

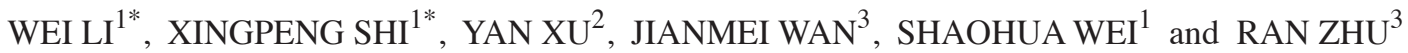 \\ ${ }^{1}$ Department of General Surgery, Second Affiliated Hospital of Soochow University; ${ }^{2}$ Department of General Surgery, \\ First Affiliated Hospital of Soochow University; ${ }^{3}$ Jiangsu Provincial Key Laboratory of Radiation Medicine and Protection, \\ School of Radiation Medicine and Protection, Medical College of Soochow University, Collaborative Innovation Center \\ of Radiation Medicine, Jiangsu Higher Education Institutions, Suzhou, Jiangsu 215123, P.R. China
}

Received March 29, 2016; Accepted March 14, 2017

DOI: $10.3892 / \mathrm{mmr} .2017 .6603$

\begin{abstract}
Tamoxifen (TAM) is the earliest non-steroidal antiestrogen drug, which has been widely used in endocrine therapy targeting breast cancer. The aim of the present study was to investigate the effect of TAM on the proliferation, apoptosis, migration and invasion of the estrogen-positive (ER+) breast cancer cell line MCF-7 in vitro, and elucidate its mechanisms. It was demonstrated that TAM suppressed proliferation, migration and invasion, and induced apoptosis in MCF-7 cells. Further investigation revealed that the mitochondrial membrane potential and the amount of ATP were significantly decreased following the treatment of MCF-7 cells with TAM. Mitochondria are an important source of reactive oxygen species (ROS) and they are also the target of ROS as well. In the present study, TAM promoted the formation of ROS in MCF-7 cells. In conclusion, these results reveal the underlying mechanism by which TAM induces ER+ breast cancer cell apoptosis and inhibits invasion, thereby supporting the use of TAM in breast cancer treatment.
\end{abstract}

Correspondence to: Dr Ran Zhu, Jiangsu Provincial Key Laboratory of Radiation Medicine and Protection, School of Radiation Medicine and Protection, Medical College of Soochow University, Collaborative Innovation Center of Radiation Medicine, Jiangsu Higher Education Institutions, 199 Ren'ai Road, Suzhou Industrial Park, Suzhou, Jiangsu 215123, P.R. China

E-mail: qhk77@sina.com

Professor Shaohua Wei, Department of General Surgery, Second Affiliated Hospital of Soochow University, 181 Sanxiang Road, Suzhou, Jiangsu 215123, P.R. China

E-mail: sdzoushitao@126.com

*Contributed equally

Key words: tamoxifen, estrogen-positive, mitochondrial membrane potential, reactive oxygen species

\section{Introduction}

Breast cancer is one of the most common female malignant tumors, and its incidence is increasing every year $(1,2)$. However, the global mortality rate of breast cancer is falling due to the established system of breast cancer screening and early diagnosis, as well as improvements in molecular biological techniques and comprehensive diagnosis and treatments (3). The first known use of endocrine therapy to treat breast cancer was in 1896 by the British scholar Beatson, who treated premenopausal advanced breast cancer using oophorectomy, and it has been recognized to be a postoperative adjuvant treatment of early breast cancer and as a treatment of advanced metastatic breast cancer (4).

Tamoxifen (TAM), the earliest selective estrogen receptor (ER) modulator, has been widely used for the treatment or prevention of estrogen receptor-positive (ER+) breast cancer, as well as for chemoprevention in women at high risk of developing breast cancer (5). Tamoxifen is composed of a triphenylethylene backbone structure and functions by combining with ER $\alpha$ (6) and inhibiting the estradiol (E2)-ER genetic pathway, which inhibit proliferation and induce apoptosis in breast cancer cells. In all breast tumor types, $75 \%$ are $\mathrm{ER} \alpha$ positive and thus tamoxifen is the most widely used therapy for breast cancer, leading to tumor stabilization in $\sim 50 \%$ of all previously untreated patients with metastatic breast cancer $(7,8)$.

There are two possible antitumor mechanisms underlying TAM, which may produce these effects. TAM is able to inhibit activation function 2 (AF2) of the ER, produce antiestrogen function $\mathrm{E}$ and alter its structure by combining with the ER (9). In addition, TAM may induce apoptosis in breast cancer cells through the membrane receptor pathway, the release of cytochrome $c(\mathrm{Cyt} \mathrm{C})$ and the biochemical pathways activated by caspase family proteins (10). TAM also inhibits protein kinase $\mathrm{C}$ activity and the extracellular signal-regulated kinase $1 / 2$ signaling pathway to modulate the growth of breast cancer cells (11). However, the exact mechanism underlying the effect of TAM on breast cancer cell growth and metastasis remains unclear.

The present study was designed to investigate the role of TAM on the growth and invasion of MCF-7 (ER+) cells 
in vitro. TAM significantly induced MCF-7 cell apoptosis, and inhibited cell growth, migration and invasion. In addition, the effect of TAM on the mitochondrial membrane potential (MMP), energy metabolism (ATP) and reactive oxygen species (ROS) in MCF-7 cells was investigated.

\section{Materials and methods}

Cell culture. The human breast cancer cell line MCF-7 was obtained from the Shanghai Cell Bank (Shanghai, China). Cells were cultured in Dulbecco's modified Eagle's medium (DMEM; Hyclone; GE Healthcare Life Sciences, Logan, UT, USA) supplemented with $10 \%$ fetal bovine serum (FBS; Hyclone; GE Healthcare Life Sciences) at $37^{\circ} \mathrm{C}$ in a humid environment with $5 \% \mathrm{CO}_{2}$.

Cell survival assay. Human breast cancer cells MCF-7 were inoculated in a 96-well plate with $100 \mu 1$ culture medium/well at density of $5 \times 10^{3}$ cells. The cells were treated with $0,0.25$, $0.50,0.75,1.0,1.25,1.5,2.0,2.5,3.0$ and $4.0 \mu \mathrm{M}$ TAM (Sigma-Aldrich; Merck KGaA, Darmstadt, Germany) for $24 \mathrm{~h}$ at $37^{\circ} \mathrm{C}$. Alternatively, cells were pretreated with $5 \mathrm{mM}$ $\mathrm{N}$-acetylcysteine (NAC; Sigma-Aldrich; Merck KGaA) for $1 \mathrm{~h}$ at $37^{\circ} \mathrm{C}$, and then treated with $0.5,1.0,2.0,3.0,4.0,5.0,6.0$, 8.0 and $10.0 \mu \mathrm{M}$ TAM for $24 \mathrm{~h}$ at $37^{\circ} \mathrm{C}$. Cell proliferation was measured using a Cell Counting kit-8 (CCK-8) assay (Beyotime Institute of Biotechnology, Haimen, China). A total of $10 \mu \mathrm{l}$ CCK-8 solution was added to each well and the cells were incubated for $2 \mathrm{~h}$ at $37^{\circ} \mathrm{C}$. The optical density (OD) was measured at $450 \mathrm{~nm}$ with a microplate reader (Thermo Fisher Scientific, Inc., Waltham, MA, USA). The cell survival fraction was calculated as the Survival fraction $=\mathrm{OD}_{\text {Experimental }} / \mathrm{OD}_{\text {Control }}$. Three independent experiments were performed in quadruplicate.

Flow cytometric analysis of the cell cycle and apoptosis. MCF-7 cells were plated in 6-well plates at a cell density of $3 \times 10^{5}$ cells and incubated until the anchoring rate was between 70 and $80 \%$. The cells were treated with $0,1,2$ and $4 \mu \mathrm{M}$ TAM for $48 \mathrm{~h}$ at $37^{\circ} \mathrm{C}$. Cells from each experimental group were collected and fixed with $70 \%$ ice-cold ethanol at $4^{\circ} \mathrm{C}$ overnight. Cells were centrifuged at $150 \mathrm{x} \mathrm{g}$ for $5 \mathrm{~min}$ at room temperature and resuspended with $500 \mu 1$ propidium iodide (PI; $100 \mu \mathrm{g} / \mathrm{ml}$ ) for $30 \mathrm{~min}$ in the dark at room temperature, prior to analysis. The cell cycle profiles were assayed using the FACScan ESP flow cytometer (BD Biosciences, San Jose, CA, USA) at $488 \mathrm{~nm}$, and data were analyzed using MultiCycle AV software for Windows 32-bit (Phoenix Flow Systems, San Diego, CA, USA). For analysis of apoptosis, cells from each experimental group were collected and processed as described in the Annexin V-Fluorescein Isothiocyanate (FITC) Apoptosis Detection kit I manual (BD Biosciences) and analyzed by FACScan flow cytometry using FlowJo.7.6.2 software (BD Biosciences).

Wound-healing assay in vitro. Cells were plated in 6-well plates and allowed to form a confluent monolayer for $24 \mathrm{~h}$. The monolayer was scratched with the tip of a $200 \mu \mathrm{l}$ pipette and then washed twice with PBS to remove the floating and detached cells. Fresh serum-free medium, which contained 0,1 and $2 \mu \mathrm{M}$ TAM, was added and images of the wound area were captured

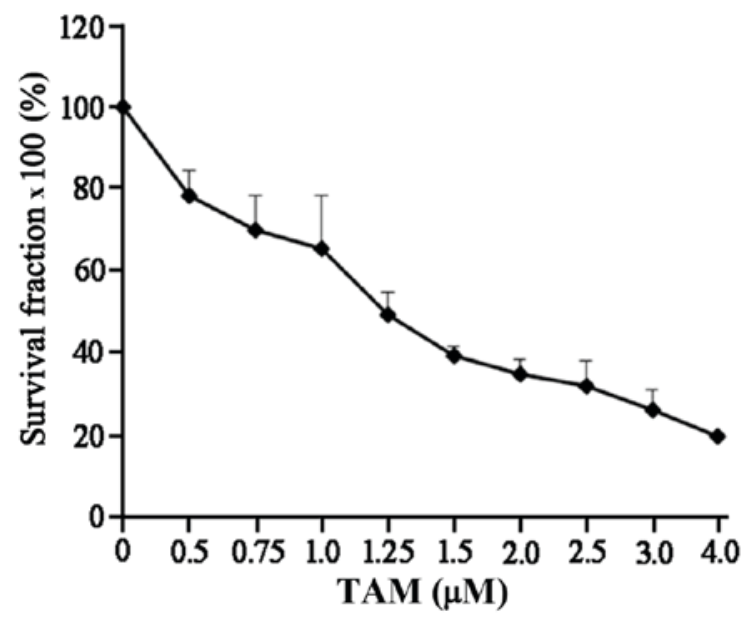

Figure 1. TAM suppresses breast cancer cell proliferation. Estrogen receptor-positive breast cancer MCF-7 cells were cultured in 96-well plates at $5 \times 10^{3}$ cells/well, and treated with $0,0.25,0.50,0.75,1.0,1.25,1.5,2.0,2.5$, 3.0 and $4.0 \mu \mathrm{M}$ TAM for $24 \mathrm{~h}$. Cell proliferation was subsequently assessed using a Cell Counting kit-8 assay. TAM, tamoxifen.

at 0,24 and $48 \mathrm{~h}$ to assess cell migration using an Olympus IX71 microscope (Olympus Corporation, Tokyo, Japan).

Transwell invasion assay. Cell invasion was assessed using 24-well Matrigel invasion chambers (Corning Incorporated, NY, USA). The inserts were pre-coated with $40 \mu$ l Matrigel (dilution, 1:4; BD Biosciences). Cells were suspended in serum-free DMEM, which contained 0 or $1 \mu \mathrm{M}$ TAM. Subsequently, $1 \times 10^{4}$ cells were added to the upper chambers. The lower chambers were filled with medium containing $10 \%$ FBS. Following incubation for $24 \mathrm{~h}$ at $37^{\circ} \mathrm{C}$, the chambers were fixed with $3.7 \%$ paraformaldehyde for $10 \mathrm{~min}$, and stained with $2 \%$ crystal violet for $30 \mathrm{~min}$ at room temperature. The penetration of cells through the membrane was quantified by counting the number of cells that penetrated the membrane in 10 microscopic fields/filter (x100).

MMP test. MCF-7 cells were plated in 6-well plate and incubated until the anchoring rate reached 70 to $80 \%$. Cells $\left(1 \times 10^{6}\right)$ were treated with $0,1,2$ and $4 \mu \mathrm{M}$ TAM for $24 \mathrm{~h}$ and trypsinized to obtain single-cell suspensions. Subsequently, cells were incubated in $0.5 \mathrm{ml} 1 \mathrm{X}$ JC-1 (Thermo Fisher Scientific, Inc.) for $15 \mathrm{~min}$ at $37^{\circ} \mathrm{C}$ and analyzed using a FACSCalibur flow cytometer with FlowJo.7.6.2 software.

ROS analysis. MCF-7 cells were plated in 6-well plates at a cell density of $3 \times 10^{5}$ cells and allowed to attach overnight. Cells were treated with $0,1,2$ and $4 \mu \mathrm{M}$ TAM for $24 \mathrm{~h}$. Cells were harvested, resuspended in serum-free DMEM containing $10 \mu \mathrm{mol} / 1$ chloromethyl-2',7'-dichlorofluorescein diacetate (Beyotime Institute of Biotechnology) and incubated at $37^{\circ} \mathrm{C}$ in the dark for $30 \mathrm{~min}$. The cells were subsequently washed three times with PBS and the intensity of fluorescence was assayed using the FC500 flow cytometer at $488 \mathrm{~nm}$.

ATP determination. MCF-7 cells were plated in 6-well plates at a cell density of $1 \times 10^{5}$ and allowed to attach overnight. Cells were treated with $0,1,2$ and $4 \mu \mathrm{M}$ TAM for $24 \mathrm{~h}$ and lysed 
A
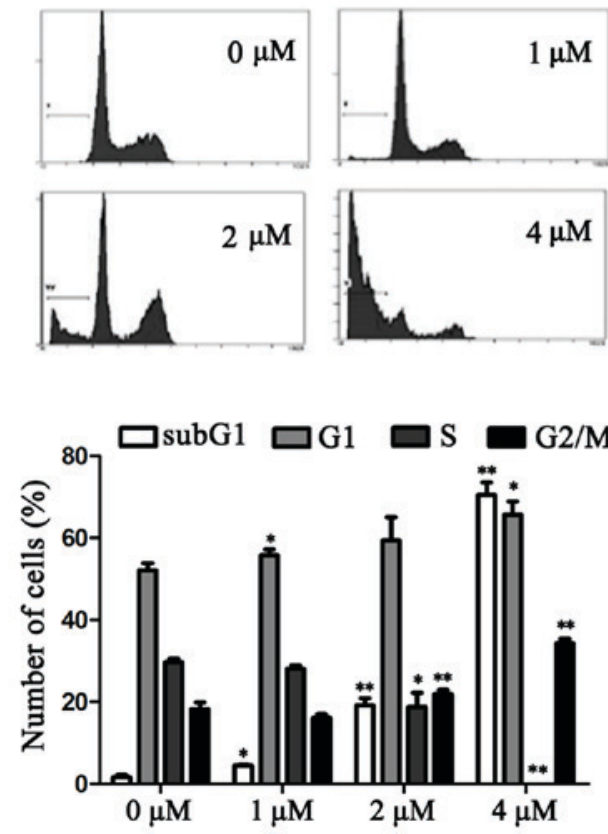

B
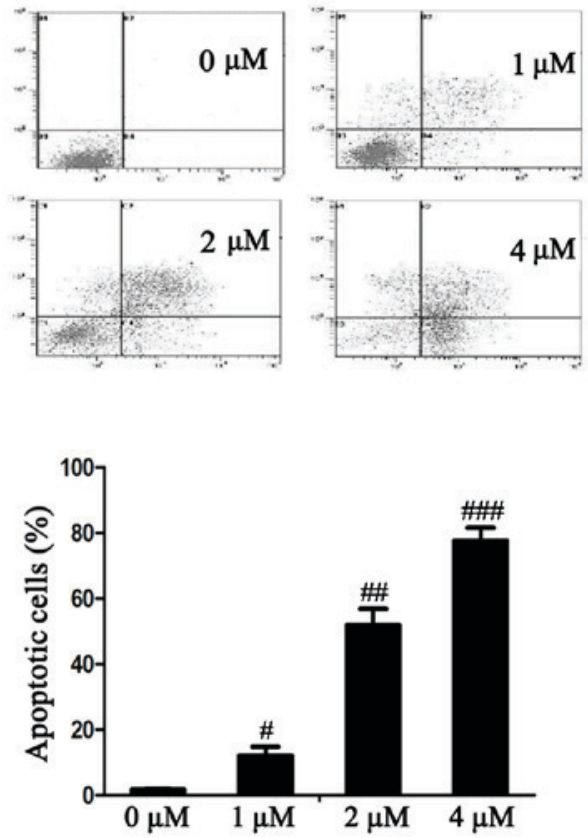

Figure 2. TAM induces cell cycle arrest and promotes cell apoptosis. Cells were treated with 0, 1, 2 and $4 \mu \mathrm{M}$ TAM for 48 h. (A) Cell cycle distribution was detected using flow cytometry. TAM induced G0/G1, G2/M and sub-G1 phase arrest in MCF-7 cells. (B) Annexin V-fluorescein isothiocyanate staining was used to determine the percentage of apoptotic cells. Data are presented as the mean \pm standard deviation. ${ }^{*} \mathrm{P}<0.05{ }^{* * *} \mathrm{P}<0.01$ vs. the respective cell cycle stage following treatment with $0 \mu \mathrm{M}$ TAM. ${ }^{\#} \mathrm{P}<0.05,{ }^{\# \#} \mathrm{P}<0.01$ and ${ }^{\# \# \#} \mathrm{P}<0.001$ vs. $0 \mu \mathrm{M}$ TAM (control). TAM, tamoxifen.

using $200 \mu \mathrm{l}$ lysis buffer (Beyotime Institute of Biotechnology). A total of $100 \mu 1$ ATP Assay kit (Beyotime Institute of Biotechnology) was added into each well of a 96-well plate and incubated at room temperature for 3 to $5 \mathrm{~min}$ to remove the background ATP. Subsequently, $100 \mu \mathrm{l}$ of sample was added to each well and ATP was analyzed on a flow cytometer following mixing.

Western blot analysis. Cells were washed with PBS and lysed in cell lysis buffer containing $1 \mathrm{X}$ phenylmethylsulfonyl fluoride (Beyotime Institute of Biotechnology, China) for $30 \mathrm{~min}$. Protein concentration was determined by BCA Protein Assay kit (Beyotime Institute of Biotechnology). Proteins $(50 \mu \mathrm{g})$ from each group were separated by $10 \%$ SDS-PAGE, transferred onto nitrocellulose membranes and blocked with 5\% skimmed milk for $1 \mathrm{~h}$ at room temperature. Following blocking, the membranes were incubated with antibodies against $\beta$-actin (1:1,000, \#3700), apoptosis regulator Bcl-2 (1:1,000, \#15071), apoptosis regulator $\mathrm{BAX}(1: 1,000, \# 5023)$ or caspase-3 (1:1,000, \#9662) (all from Cell Signaling Technology, Inc., Danvers, MA, USA) over night at $4^{\circ} \mathrm{C}$. Blots were subsequently incubated with horseradish peroxidase-conjugated anti-mouse $(1: 2,000, \# 7076)$ or anti-rabbit IgG antibodies $(1: 2,000$, \#7074) (both from Cell Signaling Technology, Inc.) for $1 \mathrm{~h}$ at room temperature. Protein bands were visualized with enhanced chemiluminescence solution (Beyotime Institute of Biotechnology).

Statistical analysis. The data are presented as the mean \pm standard deviation. SPSS software (version 19; IBM SPSS, Armonk, NY, USA) was used to perform the statistical analysis. The data were analyzed using a paired Student's t-test. $\mathrm{P}<0.05$ was considered to indicate a statistically significant difference. Each experiment was repeated three times.

\section{Results}

TAM suppresses breast cancer cell proliferation. Breast cancer cells were treated with varying concentrations of TAM to investigate the effect of TAM on cell proliferation. As presented in Fig. 1, the proliferation of these cells was markedly suppressed by TAM in a dose-dependent manner.

TAM induces cell cycle arrest and promotes cell apoptosis in breast cancer cells. The effects of TAM on the MCF-7 cell cycle were further investigated. Following treatment with TAM for $24 \mathrm{~h}$, the number of MCF-7 cells in the G0/G1 and G2/M phases increased when compared with the untreated cells. By contrast, in the $\mathrm{S}$ phase the number of cells decreased. In addition, as the concentration of TAM increased, the SubG1 Peak also significantly increased ( $\mathrm{P}<0.05$; Fig. 2A).

The effects of TAM on cell apoptosis were determined using an Annexin V-FITC and PI staining assay. As presented in Fig. 2B, TAM induced MCF-7 cell apoptosis and the percentage of apoptotic cells significantly increased in a dose-dependent manner $(\mathrm{P}<0.05)$.

TAM inhibits breast cancer cell migration and invasion. Cancer metastasis is a complex process that involves cell migration and invasiveness. To examine the effect of TAM on the migration of breast cancer cells, MCF-7 cells were subjected to in vitro wound healing assays. Confluent cell cultures were scraped to create a wound and were subsequently treated with three concentrations of TAM. Cell motility was determined at 
A
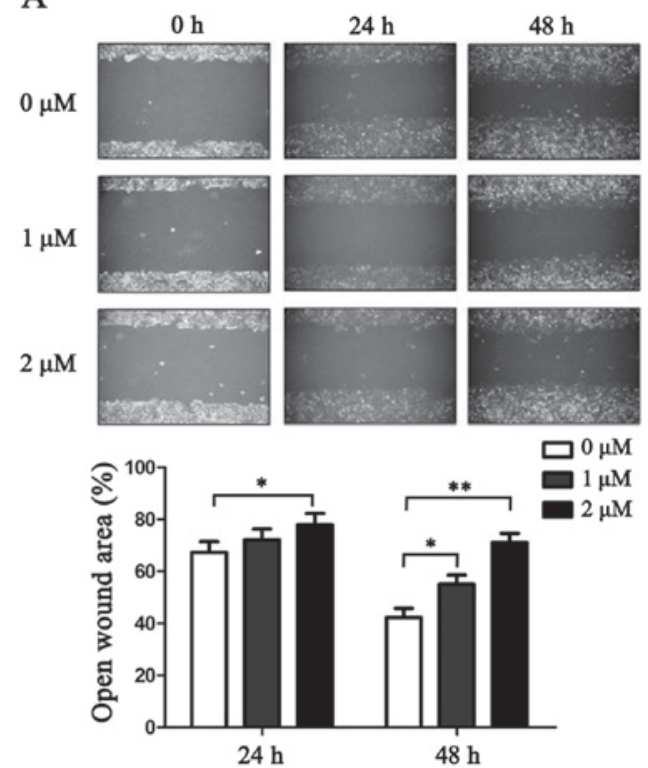

B
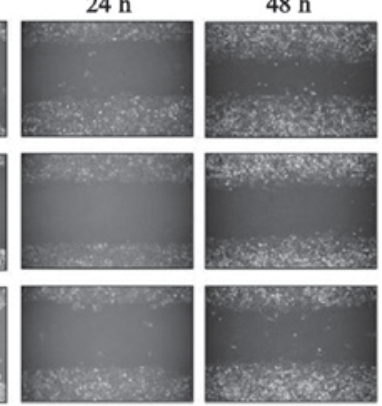
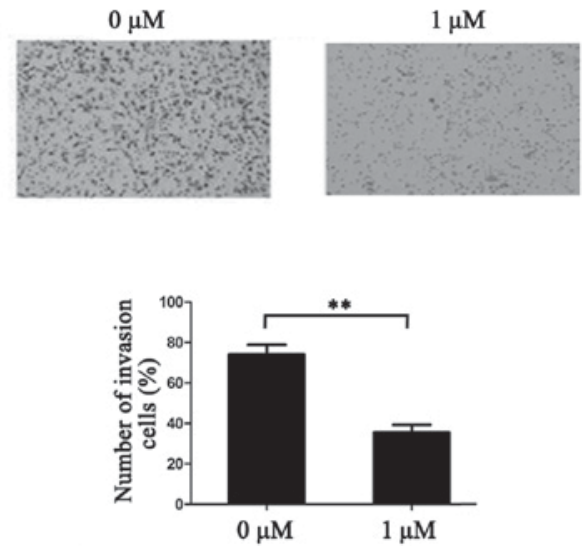

Figure 3. TAM inhibits breast cancer cell migration and invasion. (A) A wound healing assay was performed to examine cell migration. Cells were seeded in 6-well plates and treated with TAM. Wound healing was measured at 0,24 and $48 \mathrm{~h}$ following scratch wound generation (magnification, $\mathrm{x} 40$ ). The open wound area was normalized to the area at the initial time $(0 \mathrm{~h})$. TAM markedly reduced the wound area in MCF-7 cells. (B) A Matrigel transwell assay was performed to determine cell invasion potential. Cells $\left(1 \times 10^{5}\right)$ were treated with TAM and plated in transwell inserts. Cells migrated to the bottom were stained with crystal violet and calculated manually (magnification, x100). TAM treatment significantly decreased the ability of MCF-7 cells to invade through the Matrigel when compared with control cells. Data are presented as the mean \pm standard deviation. ${ }^{*} \mathrm{P}<0.05$ and ${ }^{* *} \mathrm{P}<0.01$. TAM, tamoxifen.

different time points. As presented in Fig. 3A, TAM reduced the rate of wound healing in MCF-7 cell. The effect of inhibition was enhanced with increased concentrations of TAM.

Matrigel invasion assays were performed to explore the effect of TAM on the invasiveness of breast cancer cells. Following treatment for $24 \mathrm{~h}$, the migratory cells at the bottom surface of the membrane were stained with crystal violet and cell penetration through the membrane was calculated manually. As presented in Fig. 3B, TAM treatment significantly decreased the ability of MCF-7 cells to invade through the Matrigel when compared with the control cells $(\mathrm{P}<0.01)$.

TAM reduces MMP in ER-positive breast cancer cells. A decrease in MMP is a sign of early cell apoptosis. Once the MMP has decreased, apoptosis is irreversible (12). The fluorescent dye $\mathrm{JC}-1$ is widely-used for detecting the functionality of mitochondria. Following treatment with TAM for $24 \mathrm{~h}$, the fluorescence intensity significantly decreased in MCF-7 $(\mathrm{P}<0.05$; Fig. 4A), which indicates that TAM may mediate MMP dysfunction. In addition, the expression levels of anti-apoptotic factor Bcl-2 and pro-apoptotic factors Bax and caspase-3, which are involved in the mitochondrial apoptosis pathway, were detected. As presented in Fig. 4B, TAM reduced the expression of $\mathrm{Bcl}-2$ and caspase-3, and increased the expression of Bax. These results indicate that the promotion of cell apoptosis by TAM may be mediated by the mitochondrial apoptosis pathway.

To investigate the variation of energy metabolism in cells following TAM-induced suppression of proliferation, the level of ATP in MCF-7 cells was measured. As presented in Fig. 4C, following treatment with 1,2 and $4 \mu \mathrm{M}$ TAM, the production of ATP significantly decreased in a dose-dependent manner
$(\mathrm{P}<0.05)$. These results indicate that TAM may have reduced the production of ATP and thus, energy production was not able to be compensated due to mitochondrial dysfunction. This may be one of the important mechanisms underlying TAM-induced ER-positive breast cancer cell death.

TAM promotes the formation of ROS in ER-positive breast cancer cells. Accumulation of intracellular ROS may activate a number of pathways that are important for the induction of apoptosis and inhibition of invasion $(13,14)$. Therefore, the present study examined the involvement of ROS in TAM-induced ER-positive breast cancer cell death. Following treatment with 1,2 and $4 \mu \mathrm{M}$ TAM for $24 \mathrm{~h}$, the levels of ROS in MCF-7 cells were 1.3, 2.4 and 3.1 times higher when compared with the control group, respectively $(\mathrm{P}<0.05$; Fig. 5A). To further elucidate the role of ROS in TAM-induced cell death, NAC (a type of ROS inhibitor) was used in conjunction with TAM to treat MCF-7 cells, then cell proliferation was determined using a CCK-8 assay. As presented in Fig. 5B, NAC prevented TAM-induced MCF-7 cell death. These results indicate that TAM promotes the formation of ROS in ER-positive breast cancer cells, thereby inducing cell death.

\section{Discussion}

TAM, the earliest synthetic selective estrogen receptor modulator non-steroidal antiestrogen drug, has been widely used in endocrine therapies for breast cancer (5). Estrogen specifically binds with ER forming E2-ER complexes to activate a number of transcription factors including, c-Myc, transforming growth factor (TGF)- $\alpha$ and cathepsin D, which promote cell growth and metastasis (15-17). TAM 
A
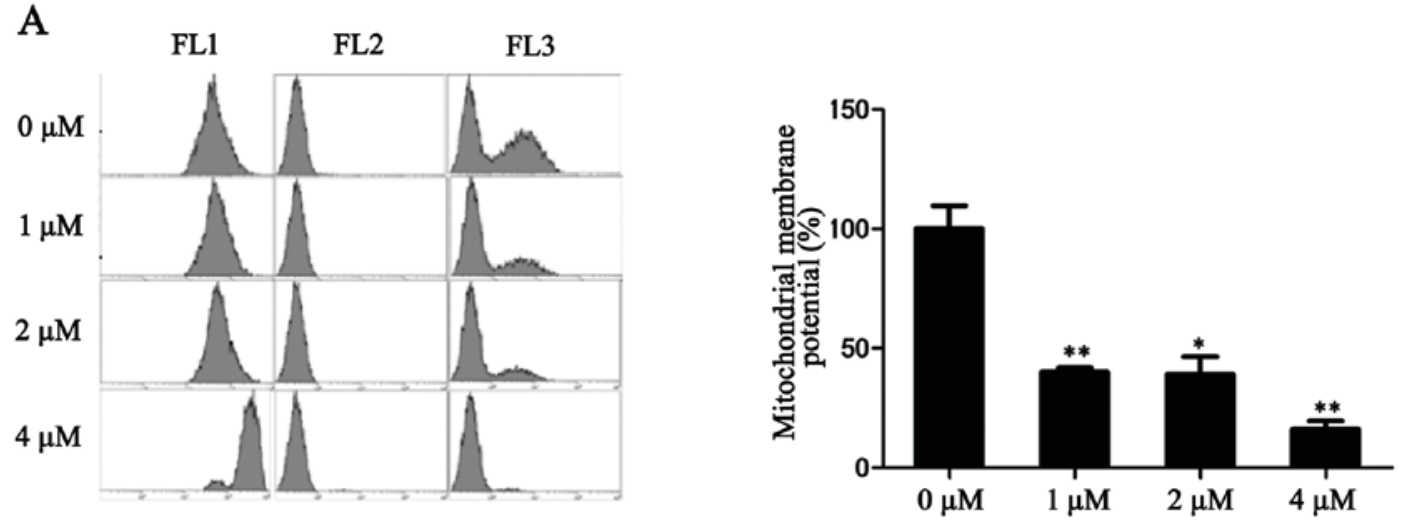

B

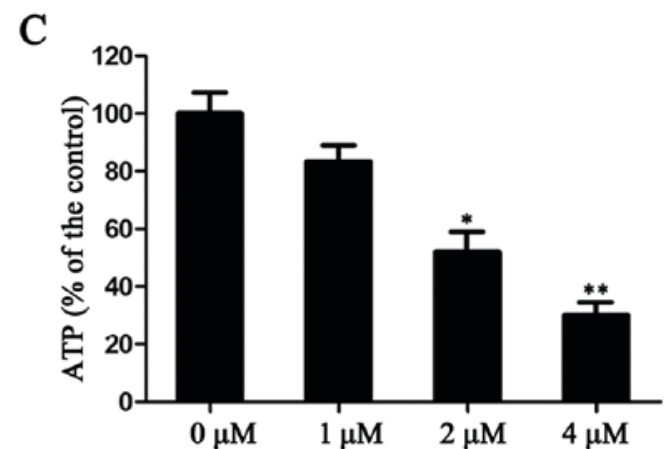

Figure 4. TAM reduces mitochondrial membrane potential in MCF-7 cells. (A) MCF-7 cells were treated with 0, 1, 2 and $4 \mu \mathrm{M}$ TAM for $24 \mathrm{~h}$, then incubated with JC-1 for $15 \mathrm{~min}$ and analyzed by flow cytometry. TAM markedly reduced JC-1 fluorescence intensity. (B) Western blotting was used to detect protein expression following cell treatment with TAM. (C) Cells were treated with 0,1,2 and $4 \mu \mathrm{M}$ TAM for $24 \mathrm{~h}$ and the level of ATP was determined using an ATP Assay kit. TAM decreased the production of ATP. Data are presented as the mean \pm standard deviation. ${ }^{*} \mathrm{P}<0.05$ and ${ }^{* *} \mathrm{P}<0.01$ vs. $0 \mu \mathrm{M}$ TAM (control). TAM, tamoxifen; Bcl-2, apoptosis regulator Bcl-2; Bax, apoptosis regulator BAX.
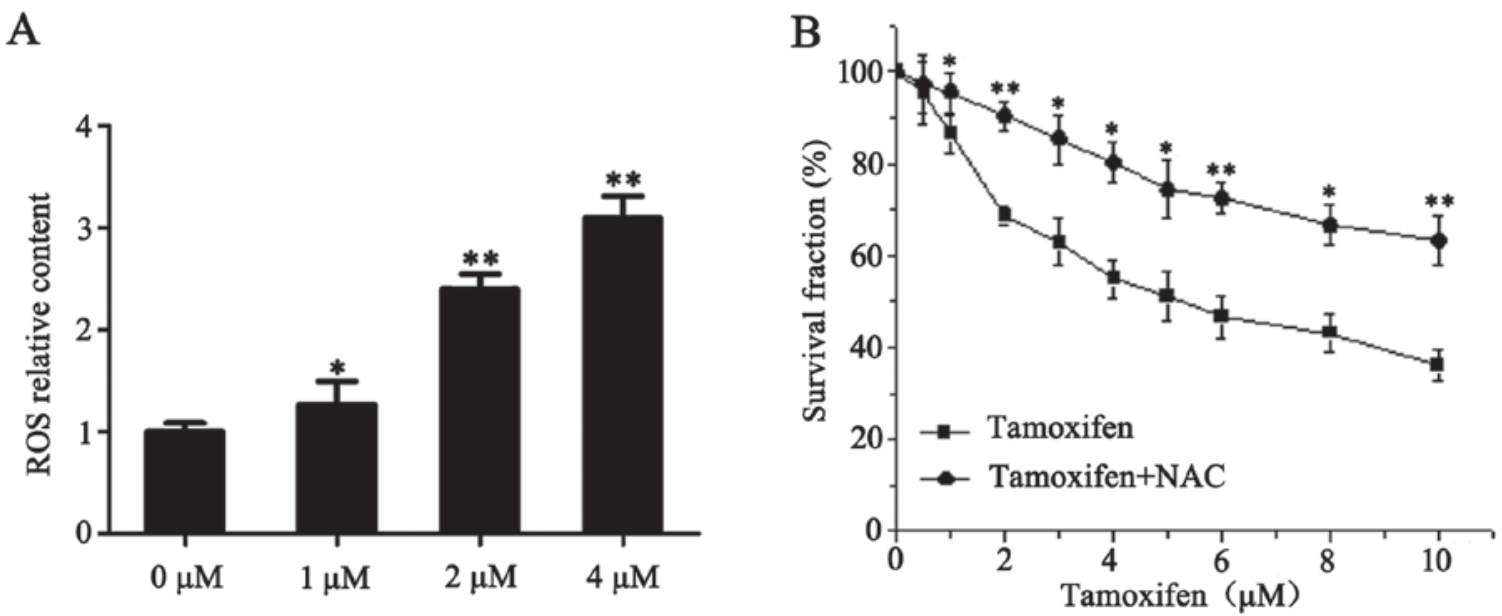

Figure 5. TAM promotes the formation of ROS in MCF-7 cells. (A) MCF-7 cells were seeded in 6-well plates and treated with 1,2 and $4 \mu \mathrm{M}$ TAM for $24 \mathrm{~h}$. The levels of ROS were 1.3,2.4 and 3.1 times higher when compared with the control group. (B) Cells were cultured in 96-cell plates and treated with TAM and the ROS inhibitor NAC. Cell proliferation was assessed by a Cell Counting kit-8 assay. NAC suppressed TAM-induced MCF-7 cell death. Data are presented as the mean \pm standard deviation. ${ }^{*} \mathrm{P}<0.05$ and ${ }^{* *} \mathrm{P}<0.01$ vs. TAM alone at each time point. TAM, tamoxifen; ROS, reactive oxygen species; NAC, $\mathrm{N}$-acetylcysteine.

competes with estrogen to bind the ER, thereby preventing proliferative stimulation by estrogens (18). A low concentration of TAM activates ER-dependent pathways, while a high concentration of TAM induces the oxidative stress reaction and activates non-ER pathways to induce cell apoptosis $(19,20)$. TAM may participate in the regulation of cell apoptosis-associated signaling pathways and directly control the mitochondrial apoptosis pathway by regulating the expression of Bcl-2/Bcl-2-like protein 1 and $\mathrm{Bax} / \mathrm{Bcl}-2$ homologous antagonist killer family of proteins (21). TAM may also regulate cell cyclin proteins (22-24), calmodulin (25) and TGF expression (26). However, the exact mechanism of the 
effect of TAM on breast cancer cell growth remains unclear, and the role of TAM on breast cancer metastasis is unknown.

In the present study, the effect of TAM on the growth, cell cycle progression and apoptosis of ER+ MCF-7 cells was investigated. The results demonstrated that there is a dose-dependent association between TAM and its effect on MCF-7 cell growth. In addition, TAM induced G0/G1 and G2/M phase arrest in MCF-7 cells and significantly promoted MCF-7 cell apoptosis.

A high degree of invasiveness is an important feature of malignant tumors and is the basic cause of tumor recurrence. Due to the development of radiotherapy and chemotherapy, the local control of breast cancer has improved; however, distant metastasis has been the primary cause of treatment failure. In the present study, following treatment with TAM, the migration and invasiveness of MCF-7 cells was markedly reduced.

Since Warburg's initial hypothesis (27) the role of mitochondrial dysfunction in tumorigenesis has been investigated extensively using multiple approaches $(12,28)$. The results of the present study indicate that the MMP became unstable and decreased in MCF-7 cells, observed as a decrease in JC-1 accumulation within mitochondria. In addition, the level of ATP decreased with increasing concentrations of TAM, which indicated that the cell energy metabolism was inhibited and the decline in ATP could not be compensated by the tricarboxylic acid cycle. Stabilization of the mitochondrial membrane is also controlled by Bcl-2 family members. This family is composed of a number of pro-apoptotic and anti-apoptotic proteins that heterodimerize and modulate each other's function (29). In the present study, the anti-apoptotic protein Bcl-2 was downregulated and the pro-apoptotic protein Bax was upregulated following MCF-7 cell treatment with TAM. In addition, the expression of caspase-3, a protein associated with the mitochondrial apoptosis pathway, decreased with increasing TAM concentrations.

Mitochondria are an important source of ROS and are also the target of ROS (30). Previously, studies have demonstrated that elevated ROS may induce damage to the mitochondrial membrane, causing cell cycle progression arrest (31) and cell apoptosis (13). The involvement of ROS signaling in tumor metastasis has also been revealed (14). In the present study, following treatment with TAM for $24 \mathrm{~h}$, the level of ROS significantly increased in MCF-7 cells. Notably, NAC (a type of ROS inhibitor) was able to prevent TAM-induced MCF-7 cell death.

In conclusion, the present study demonstrated that TAM was able to specifically inhibit the growth and invasion of ER+ MCF-7 breast cancer cells, and induce G0/G1 and G2/M phase arrest, and cell apoptosis in MCF-7 cells. The level of ATP reduced and the MMP decreased, in conjunction with an increase in ROS, contributing to apoptosis and the inhibition of invasion in MCF-7 cells. These results support the theoretical foundations for the targeted therapy of breast cancer.

\section{Acknowledgements}

The present study was supported by the National Natural Science Foundation of China (grant no. 81502758), the Science and Technology Foundation of Suzhou (grant no. SYS201417), and a Project Funded by the Priority Academic Program Development of Jiangsu Higher Education Institutions.

\section{References}

1. Printz C: American Cancer Society reports progress in reducing cancer deaths: However, some groups still lag behind this trend. Cancer 117: 4573-4574, 2011.

2. Chen W, Zheng R, Baade PD, Zhang S, Zeng H, Bray F, Jemal A, $\mathrm{Yu}$ XQ and He J: Cancer statistics in China, 2015. CA Cancer J Clin 66: 115-132, 2016.

3. Lash TL, Fox MP and Silliman RA: Reduced mortality rate associated with annual mammograms after breast cancer therapy. Breast J 12: 2-6, 2006.

4. Montemurro F, Del Mastro L, De Laurentiis M and Puglisi F: Endocrine therapy in premenopausal women with breast cancer: A critical appraisal of current evidence. Expert Rev Anticancer Ther 16: 211-218, 2016.

5. Fisher B, Costantino JP, Wickerham DL, Redmond CK, Kavanah M, Cronin WM, Vogel V, Robidoux A, Dimitrov N, Atkins J, et al: Tamoxifen for prevention of breast cancer: Report of the National Surgical Adjuvant Breast and Bowel Project P-1 Study. J Natl Cancer Inst 90: 1371-1388, 1998.

6. Jordan VC: Tamoxifen: A most unlikely pioneering medicine. Nat Rev Drug Discov 2: 205-213, 2003.

7. Ring A and Dowsett M: Mechanisms of tamoxifen resistance. Endocr Relat Cancer 11: 643-658, 2004.

8. Jaiyesimi IA, Buzdar AU, Decker DA and Hortobagyi GN: Use of tamoxifen for breast cancer: Twenty-eight years later. J Clin Oncol 13: 513-529, 1995.

9. Glaros S, Atanaskova N, Zhao C, Skafar DF and Reddy KB: Activation function-1 domain of estrogen receptor regulates the agonistic and antagonistic actions of tamoxifen. Mol Endocrinol 20: 996-1008, 2006.

10. Li Z, Carrier L and Rowan BG: Methylseleninic acid synergizes with tamoxifen to induce caspase-mediated apoptosis in breast cancer cells. Mol Cancer Ther 7: 3056-3063, 2008.

11. Li Z, Wang N, Fang J, Huang J, Tian F, Li C and Xie F: Role of PKC-ERK signaling in tamoxifen-induced apoptosis and tamoxifen resistance in human breast cancer cells. Oncol Rep 27: 1879-1886, 2012.

12. Cavalli LR and Liang BC: Mutagenesis, tumorigenicity, and apoptosis: Are the mitochondria involved? Mutat Res 398: 19-26, 1998.

13. Simon HU, Haj-Yehia A and Levi-Schaffer F: Role of reactive oxygen species (ROS) in apoptosis induction. Apoptosis 5: 415-418, 2000.

14. Storz P: Reactive oxygen species in tumor progression. Front Biosci 10: 1881-1896, 2005.

15. Katzenellenbogen BS, Fang H, Ince BA, Pakdel F, Reese JC, Wooge CH and Wrenn CK: William L. McGuire Memorial Symposium. Estrogen receptors: Ligand discrimination and antiestrogen action. Breast Cancer Res Treat 27: 17-26, 1993.

16. Katzenellenbogen BS, Montano MM, Le Goff P, Schodin DJ, Kraus WL, Bhardwaj B and Fujimoto N: Antiestrogens: Mechanisms and actions in target cells. J Steroid Biochem Mol Biol 53: 387-393, 1995.

17. Amin S, Kumar A, Nilchi L, Wright K and Kozlowski M: Breast cancer cells proliferation is regulated by tyrosine phosphatase SHP1 through c-jun N-terminal kinase and cooperative induction of RFX-1 and AP-4 transcription factors. Mol Cancer Res 9: 1112-1125, 2011.

18. Mandlekar S and Kong AN: Mechanisms of tamoxifen-induced apoptosis. Apoptosis 6: 469-477, 2001.

19. Mamay CL, Mingo-Sion AM, Wolf DM, Molina MD and Van Den Berg CL: An inhibitory function for JNK in the regulation of IGF-I signaling in breast cancer. Oncogene 22: 602-614, 2003.

20. Montano MM and Katzenellenbogen BS: The quinone reductase gene: A unique estrogen receptor-regulated gene that is activated by antiestrogens. Proc Natl Acad Sci USA 94: 2581-2586, 1997.

21. Nazarewicz RR, Zenebe WJ, Parihar A, Larson SK, Alidema E, Choi J and Ghafourifar P: Tamoxifen induces oxidative stress and mitochondrial apoptosis via stimulating mitochondrial nitric oxide synthase. Cancer Res 67: 1282-1290, 2007.

22. Umekita Y, Ohi Y, Sagara Y and Yoshida H: Overexpression of cyclinD1 predicts for poor prognosis in estrogen receptor-negative breast cancer patients. Int J Cancer 98: 415-418, 2002. 
23. Altucci L, Addeo R, Cicatiello L, Dauvois S, Parker MG, Truss M Beato M, Sica V, Bresciani F and Weisz A: 17beta-Estradiol induces cyclin D1 gene transcription, p36D1-p34cdk4 complex activation and $105 \mathrm{Rb}$ phosphorylation during mitogenic stimulation of G(1)-arrested human breast cancer cells. Oncogene 12: 2315-2324, 1996.

24. Fu XD, Cui YH, Lin GP and Wang TH: Non-genomic effects of 17beta-estradiol in activation of the ERK1/ERK2 pathway induces cell proliferation through upregulation of cyclin D1 expression in bovine artery endothelial cells. Gynecol Endocrinol 23: 131-137, 2007.

25. Pawar P, Ma L, Byon CH, Liu H, Ahn EY, Jhala N, Arnoletti JP, McDonald JM and Chen Y: Molecular mechanisms of tamoxifen therapy for cholangiocarcinoma: Role of calmodulin. Clin Cancer Res 15: 1288-1296, 2009.

26. Carthy JM, Sundqvist A, Heldin A, van Dam H, Kletsas D, Heldin CH and Moustakas A:Tamoxifen inhibits TGF- $\beta$-mediated activation of myofibroblasts by blocking non-smad signaling through ERK1/2. J Cell Physiol 230: 3084-3092, 2015.
27. Warburg O: On the origin of cancer cells. Science 123: 309-314, 1956.

28. Shay JW and Werbin H: Are mitochondrial DNA mutations involved in the carcinogenic process? Mutat Res 186: 149-160, 1987.

29. Harris $\mathrm{MH}$ and Thompson $\mathrm{CB}$ : The role of the Bcl-2 family in the regulation of outer mitochondrial membrane permeability. Cell Death Differ 7: 1182-1191, 2000.

30. Modica-Napolitano JS and Singh KK: Mitochondrial dysfunction in cancer. Mitochondrion 4: 755-762, 2004.

31. Boonstra J and Post JA: Molecular events associated with reactive oxygen species and cell cycle progression in mammalian cells. Gene 337: 1-13, 2004 